\title{
The SUBGLACIOR drilling probe: concept and design
}

\author{
O. ALEMANY, ${ }^{1}$ J. CHAPPELLAZ, ${ }^{1}$ J. TRIEST, ${ }^{1}$ M. CALZAS, ${ }^{2}$ O. CATTANI, ${ }^{3}$ \\ J.F. CHEMIN, ${ }^{1}$ Q. DESBOIS, ${ }^{4}$ T. DESBOIS, ${ }^{4}$ R. DUPHIL, ${ }^{1}$ S. FALOURD, ${ }^{3}$ R. GRILLI, ${ }^{4}$ \\ C. GUILLERME, ${ }^{2}$ E. KERSTEL, ${ }^{4}$ B. LAURENT, ${ }^{1}$ E. LEFEBVRE, ${ }^{1}$ N. MARROCCO, ${ }^{4}$ \\ O. PASCUAL, ${ }^{1}$ L. PIARD, ${ }^{1}$ P. POSSENTI, ${ }^{1}$ D. ROMANINI, ${ }^{4}$ V. THIEBAUT, $^{3}$ \\ R. YAMANI ${ }^{3}$
}

${ }^{1}$ Laboratoire de Glaciologie et Géophysique de l'Environnement (LGGE), Université Grenoble Alpes and Centre National de la Recherche Scientifique (CNRS), Grenoble, France

E-mail: alemany@lgge.obs.ujf-grenoble.fr

${ }^{2}$ Division Technique de I'INSU, Plouzane, France

${ }^{3}$ LSCE, IPSL, CEA CNRS UVSQ, Gif-sur-Yvette, France

${ }^{4}$ Laboratoire Interdisciplinaire de Physique (LIPHY), Université Grenoble Alpes and Centre National de la Recherche Scientifique (CNRS), Grenoble, France

\begin{abstract}
In response to the 'oldest ice' challenge initiated by the International Partnerships in Ice Core Sciences (IPICS), new rapid-access drilling technologies through glacier ice need to be developed. These will provide the information needed to qualify potential sites on the Antarctic ice sheet where the deepest section could include ice that is $>1 \mathrm{Ma}$ old and still in good stratigraphic order. Identifying a suitable site will be a prerequisite for deploying a multi-year deep ice-core drilling operation to elucidate the cause and mechanisms of the mid-Pleistocene transition from 40 ka glacial-interglacial cycles to $100 \mathrm{ka}$ cycles. As part of the ICE\&LASERS/SUBGLACIOR projects, we have designed an innovative probe, SUBGLACIOR, with the aim of perforating the ice sheet down to the bedrock in a single season and continuously measuring in situ the isotopic composition of the melted water and the methane concentration in trapped gases. Here we present the general concept of the probe, as well as the various technological solutions that we have favored so far to reach this goal.
\end{abstract}

KEYWORDS: climate change, glaciological instruments and methods, ice coring

\section{INTRODUCTION}

The mid-Pleistocene climatic transition which took place 1 Ma ago marks the last major feature of the Earth's climatic evolution at geological timescales. It is characterized by a shift from glacial-interglacial cycles of relatively mild amplitude that took place every 40 ka to larger-amplitude cycles that occurred every $100 \mathrm{ka}$, despite no contemporaneous change in the periodicity and amplitude of the orbital configuration of the Earth around the Sun (Lisiecki and Raymo, 2005). Such a major change in the climatic response to orbital forcing implies a reorganization of internal feedbacks, possibly involving the amount of greenhouse gases in the atmosphere and thus climate sensitivity.

The only way to accurately constrain the evolution of the atmospheric composition throughout the mid-Pleistocene transition is to determine the composition of the air trapped in the ice formed during this period. It justifies what has been called the 'oldest ice' challenge by the international ice-core community federated by the International Partnerships in Ice Core Sciences (IPICS) programme (Fischer and others, 2013). Ice as old as $1 \mathrm{Ma}$ certainly exists in the Antarctic ice sheet, where the low accumulation rate of snow at the surface favours with depth the formation of ancient ice strata. But due to the thinning of ice layers with depth and due to ice flow, the strata old enough to qualify for the 'oldest ice' challenge are located near the bedrock and may have been disturbed, thus losing the normal stratigraphic layering. The strata of interest may also have been lost due to melting at the ice/bedrock interface.Thus, a site that appears promising based on radar echo sounding and ice-flow modelling might well produce ice cores with an unsuitable stratigraphic sequence. The cost of setting up a multi-year deep ice-core drilling operation justifies taking every possible step to ensure the selected site is suitable.

As stated by Fischer and others (2013), 'we argue strongly for rapid access drilling before any full, deep ice coring activity commences to bring datable samples to the surface and to allow an age check of the oldest ice'. This is what the SUBGLACIOR probe is intended for. It aims to measure geochemical signals in situ, inside the Antarctic ice sheet and in real time during the drilling process using a built-in laser spectrometer. Hence, we do not speak of ice-core drilling, but rather of real probing of the ice sheet, where part of the ice is used for real-time measurements.

The SUBGLACIOR (in-SitU proBing of GLACier Ice for a better understanding of the Orbital Response of climate) probe will make its own way down into the ice and, relying on the progress of laser technology, will measure in real time and down to the bedrock the depth profiles of the ice $\delta \mathrm{D}$ water isotopes, as well as the trapped $\mathrm{CH}_{4}$ gas concentration. The $\delta \mathrm{D}$ values of the melted ice will deliver the baseline climatic signal in the deep ice. Their evolution with depth will allow us to tell the difference in the ice corresponding to interglacial or glacial conditions, 'count' the climatic cycles back in time and then compare them with marine reference records (Lisiecki and Raymo, 2005). Atmospheric $\mathrm{CH}_{4}$ shows significant changes between glacial and interglacial states (typically from 350 to 
$800 \mathrm{ppbv}$ ). It is an indirect tracer of Northern Hemisphere climate. As it is recorded in trapped bubbles and clathrates, and because of firnification processes, its changes are shifted with depth compared with concomitant climatic changes recorded in $\delta \mathrm{D}$ of $\mathrm{H}_{2} \mathrm{O}$. The observation of this depth shift is a primary indicator that the ice layers are still in good stratigraphic order (Chappellaz and others, 1997). Therefore, these two signals alone will yield three important pieces of information: (1) the age of the ice as a function of depth, (2) the integrity of the ice record, and (3) key climate and atmospheric signals, possibly dating back to 1.5 Ma BP.

SUBGLACIOR relies on important technological advances made in recent years in the field of laser physics and spectroscopic detection. Using near- to mid-infrared laser spectroscopy, it is now possible to accurately and precisely measure trace gas concentrations as well as the isotopic composition of water on very small gas flows and with a very compact instrument. The OF-CEAS patented methodology (Optical Feedback - Cavity Enhanced Absorption Spectroscopy, J. Morville, D. Romanini, M. Chenevier, patent WO03031949, Université J. Fourier, Grenoble FRANCE, 2003) relies on optical feedback in a high-finesse cavity, which provides very high sensitivity in a compact and robust spectrometer (Morville and others 2005, 2014).

The SUBGLACIOR probing system will include: (1) the drilling tool itself, including a built-in OF-CEAS laser system, and the associated electronics to control the device and transmit information to the surface, (2) a cable attached along a hosepipe, the cable to provide the power supply and communicate with the probe, and the hosepipe to circulate the drilling fluid and ice chips between the borehole and the surface, and (3) two winches (one for the cable and one for the hosepipe). With this ensemble, the aim is to drill down to 3000-3500 m within a single field season in Antarctica, i.e. in $<90$ days. The instrument will be carried on site by traverse vehicles.

\section{PREVIOUS RAPID-ACCESS/PROBING ATTEMPTS}

Since the early 1960s, different designs have been developed and sometimes tested to rapidly access deep ice inside an ice sheet. We summarize these below, along with other techniques that could be transposed to ice-sheet applications.

\section{The Philberth probe}

The Philberth probe was designed to measure in situ temperature (Philberth, 1962). It contained an electric heater to melt the surrounding ice. Its descent through the ice was driven by its own weight. Electric wires and sensor conductor cables were paid out from the probe during the descent and probably got sealed into the deforming ice above. Four Philberth probes were tested in Greenland by US Army Cold Regions Research and Engineering Laboratory (CRREL) engineers, the most successful reaching $1005 \mathrm{~m}$ depth in 1968. Two were tested in Antarctica by US and Australian engineers in the 1970s but were lost only $\sim 100 \mathrm{~m}$ below the surface.

\section{The 'Climatopic' probe}

Developed in the late 1970s to sample melted ice for subsequent laboratory measurements of water isotopes as a function of depth (Gillet and others, 1984), the Climatopic probe also descended under its own weight and progressed by melting the ice with an electric heater. But in this method, the cable was spooled from a drum at the surface. The melted water was stored in a large tank at the top of the probe, which was emptied at the surface at the end of each run. The probe's drawbacks included the need for roundtrips between the surface and the bottom of the hole, the relatively high amount of energy required for the various heated elements $(\sim 6 \mathrm{kVA})$, and lack of counterbalancing of the hydrostatic pressure of the ice, which tended to close the hole below $\sim 1000 \mathrm{~m}$. The probe was tested only once, in 1982 at Dome C, Antarctica, down to $235 \mathrm{~m}$.

\section{Hot-water rapid-access drilling}

Several rapid-access drilling systems have been designed to perform 'hot-water drilling' by injecting hot water under high pressure from the surface in order to obtain a fastaccess hole in the ice sheet, typically down to $2 \mathrm{~km}$ depth. This technology is used to deploy dedicated instruments, such as neutrino detectors (US AMANDA (Antarctic Muon and Neutrino Detector Array) and IceCube projects) or geophysical instruments (e.g. Koci, 1994; Makinson, 1994). But these in situ devices cannot be used to extract climaterelated information as a function of depth, because the hotwater circulation between the surface and the borehole mixes up any climatic/environmental signal that might initially have been preserved in good stratigraphic sequence in the ice sheet.

\section{Thermal probe}

Japanese engineers have designed a thermal drilling probe that could carry in situ instruments (Suto and others, 2008). With this design, the cable is not paid out from the probe itself but is spooled on a drum at the surface. The melted water produced stays in the hole and refreezes. Heat provided to the cable by Joule effect maintains a thin layer of water $(<1 \mathrm{~mm})$ around the cable, allowing it to move freely in the hole during descent. The big drawback of this design is its energy consumption. More than $150 \mathrm{kVA}$ are needed to prevent the ice around a $4000 \mathrm{~m}$ long cable from refreezing, and this requires very high and unsafe voltage $(>2 \mathrm{kV})$. The probe is not yet built nor tested.

\section{Coiled tubing and string drilling}

The coiled tubing drilling technique has been used in commercial oil and gas exploration for a very long time. The coiled tubing drill uses a metal or advanced composite tube to deliver fluid downhole to a hydraulic motor that drives a cutting head. It has recently been suggested that this principle may be adapted to drilling in ice (Clow and Koci, 2002). It could be very fast (up to $40 \mathrm{~m} \mathrm{~h}^{-1}$ for drilling in rocks). The main drawback of this solution is the very high penetration speed, which makes it difficult to perform realtime measurements. Another problem is that significant forces are required to straighten out the coil as it unwinds from the drum for it to be dropped into the borehole. Usually this is done using a very heavy industrial injector that requires a huge supply of power (either electric or hydraulic), which is a major drawback for polar ice-sheet application. In addition, with current tools, it would be very difficult to control the penetration rate accurately (with a precision greater than $1 \mathrm{~mm} \mathrm{~s}^{-1}$ ). At the moment, no industrial provider has shown interest in collaborating in the design of a special coil/injector that would take into consideration the specific constraints of ice drilling. 
Another technology used in the oil or gas industry is string drilling (e.g. Nguyen, 1993), which offers the advantage of recovering the drilled material at the surface. This is even faster than coiled tubing, but heavier and still more difficult to run accurately when a low penetration rate is required.

\section{Other ongoing projects}

Other ongoing projects, intended either to rapidly access deep ice or to continuously measure its content during probing, include a rapid-access drill called RADIX (Schwander and others, 2014) and the recoverable autonomous sonde RECAS (Talalay and others, 2014).

\section{THE SUBGLACIOR PROBE CONCEPT}

The whole concept of the SUBGLACIOR probe consists in carrying through the entire thickness of the ice sheet a builtin OF-CEAS laser spectrometer able to conduct in situ and real-time geochemical measurements along the drilled ice. This involves two main technological challenges: (1) the spectrometer must be small enough so that the whole probe dimensions are in the range of traditional ice-core drilling systems or even smaller, and (2) the drilling envelope around the spectrometer must be able to perforate the ice sheet in a single run, to continuously evacuate the drilled ice, and to produce a sample that can continuously feed the spectrometer.

Regarding the first challenge and in order to reduce the borehole diameter, and thus the volume of drilling fluid required, we managed to design an OF-CEAS spectrometer with a diameter of only $50 \mathrm{~mm}$. Taking into account the thermal insulation envelope, drilling-fluid circulation channels and outer tube, this means a maximum probe outer diameter (OD) of $110 \mathrm{~mm}$ and a borehole diameter of $120 \mathrm{~mm}$.

Regarding the second challenge, none of the technical principles mentioned in the previous section were deemed suitable for the SUBGLACIOR drilling probe. We therefore decided to combine two drilling methods: thermal drilling for a small fraction of the drilled diameter in order to provide a continuous sample of ice-trapped gas (together with a small amount of water vapour for deuterium isotopic measurements) to the OF-CEAS spectrometer, and electromechanical drilling for the remaining diameter of the borehole to accommodate the whole probe dimensions. In this way, nearly $85 \%$ of the borehole diameter (i.e. $97 \%$ of the borehole surface) will be drilled electromechanically, which is much more energy-efficient than thermal drilling.

As in any deep ice-drilling operation where the drilling system is finally recovered at the surface, the borehole must be filled with a drilling fluid that can counterbalance the hydrostatic pressure of the ice and prevent borehole closure (or at least reduce the closing rate as much as possible). During the run, the SUBGLACIOR probe will continuously produce ice chips through electromechanical drilling, and a small amount of water through thermal drilling. Because we aim for a single run from surface down to bedrock in order to save time, both the chips and liquid water must be continuously evacuated toward the surface during the probe's progression, using the drilling fluid as a carrier. Three different options were considered to reach this goal.

\section{Dissolving ice chips in the drilling fluid}

The first option considered was to dissolve the ice chips in the drilling fluid. This solution requires quickly dissolving the ice chips in the drilling fluid and keeping the resulting mixture in a liquid state and with a relatively low viscosity even at very low temperatures (down to $-55^{\circ} \mathrm{C}$ ). After conducting bibliographic and technical reviews, we could not find a suitable fluid, even after considering possible additives such as potassium acetate salts or organogels. We tested the most promising one, organogel Tween ${ }^{\circledR} 80$ mixed with ice chips, in a cold room. The ice-dissolving rate was much too slow to be suitable for application in ice probing. In addition, the chip-dissolving mixture would tend to dissolve the borehole walls as well over time, which would tend to produce highly viscous slush in the borehole. We thus discarded this option.

\section{Transfer of ice chips to the surface using an embedded pump}

We also considered carrying the ice chips to the surface by circulating the drilling fluid using a progressive cavity pump built into the drilling probe itself. With this design, the builtin pump generates an upward flow rate moving a mixture of ice chips and drilling fluid from the bottom of the borehole to the surface through a hosepipe. The main advantage of this design is that it keeps the chips inside the hosepipe. The borehole thus remains free of ice chips, thus reducing the risk of borehole clogging. We found a progressive cavity pump (Moineau type model PCM 6E600) able to fit into a small-diameter tube and provide a flow of $\sim 30 \mathrm{~L} \mathrm{~min}^{-1}$ under a relative pressure increase of several bars. We tested the pump both in the workshop and in cold rooms, on artificial mixtures of drilling fluid with plastic chips. However, it turned out that, at low temperature, this pump required far too high levels of torque $(>40 \mathrm{~N} \mathrm{~m})$. This is due to the pump design which includes a stator made of a soft material. The stator's contraction coefficient is greater than that of stainless steel, the material used for the rotor. Increasing the clearance between the rotor and the stator would reduce the required torque at low temperature, but it would deteriorate the fluid flow rate. In addition, we observed that the Moineau pump generates vibrations that could be detrimental to the stability of the OF-CEAS spectrometer also built into the probe. Therefore we discarded this solution.

\section{Transfer of the ice chips to the surface using a pump at the surface}

The solution finally selected for the SUBGLACIOR probe is for the pump to be located at the surface and to pump the clean drilling fluid down to the probe head through the hosepipe. The ice chips travel back toward the surface in the fluid column that fills the annulus between the borehole and the probe/hosepipe, due to the fluid circulation generated by the surface pump. This solution is discussed in more detail below.

\section{Probe geometry including fluid handling}

The probe (Fig. 1) will be suspended in the borehole by an electromechanical cable (to provide data and power transmission to/from the probe) and a hosepipe (to transport the fluid from the surface to the drill head). The possibility of including electric conductors in the hosepipe skin (a technique used in the past by oil companies) was 


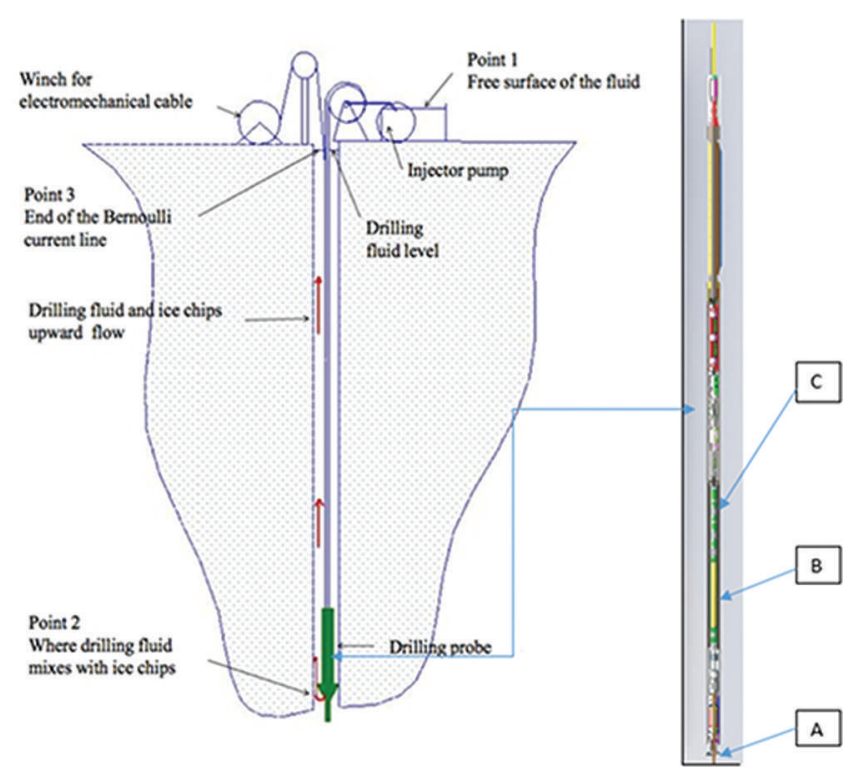

Fig. 1. Schematic of the SUBGLACIOR structure and drilling-fluid circulation.

considered. However, it would require special manufacturing which would be far too expensive for a solution not yet proven to work properly under the cold conditions of an 'oldest ice' application.

A drill head (at the tip of the probe) will cut the ice on $97 \%$ of the borehole surface. The chips generated while cutting the ice will be transported upward by the drilling fluid injected in the drill head next to the ice cutters, first into the free space between the probe and the borehole and then into the annulus section between the borehole and the hosepipe due to the flow of drilling fluid generated by the hydraulic pump at the surface. A heating element ( $A$ in Fig. 1 ) inserted at the centre of the drill head will melt $3 \%$ of the borehole surface. The mixture of water and gas coming from the melted ice will be transferred inside the probe to a samplehandling line. The latter will include a gas/water separation device made either of a membrane (which works at ambient pressure) or of a debubbler (which works under atmospheric pressure) (B in Fig. 1). The humidified gas sample will then be pumped through the embedded OF-CEAS laser spectrometer for continuous flow analysis ( $\mathrm{C}$ in Fig. 1 ).

Inside the probe itself, the fluid circulation from the top part to the drill head will follow an annular channel machined inside the outer tube, allowing the central inner part of the probe to keep dry. This dry central section (with an external diameter of $\sim 96 \mathrm{~mm}$ and an internal diameter of $84 \mathrm{~mm}$ ) will host the spectrometer, the fluid/gas separation device and the electronic sections (Fig. 2).
Because the ice chips must be recovered at the surface, it is mandatory to bring the fluid level up to the surface. This requires installing a leak-tight casing throughout the length of the porous firn column, anchored deeper into solid ice (thus typically through the upper $120 \mathrm{~m}$ of the ice sheet). This type of casing has already been developed and successfully tested at Concordia Station, Antarctica (Duphil and others, 2014).

\section{Drilling fluid}

The drilling fluid to be used during the SUBGLACIOR probe deployment must satisfy several constraints: (1) its kinematic viscosity must be $<25 \mathrm{~mm}^{2} \mathrm{~s}^{-1}$ at $-50^{\circ} \mathrm{C}$ to obtain reasonable winching speed during ascent of the probe at the end of the probing season, or even during descent if the probe must be brought back to the surface for repair during the campaign; (2) its density after being mixed with the drill chips must counterbalance partially or entirely the hydrostatic pressure of deep ice, in order to prevent hole closure; (3) it must contribute to avoiding the formation of ice-chip clusters in the borehole during ascent, which would risk clogging the borehole; (4) it must be relatively cheap, as tens of cubic metres will be required during the probing campaign; (5) its vapours must not interfere with the OF-CEAS spectrum, as there is always the possibility that a tiny amount of drilling fluid will enter the sample line during probing; (6) it must comply with the environmental considerations of the Antarctic Treaty; and (7) it must have minimal impact on the health of the operators.

After evaluating several types of fluid, we finally chose silicone oil 3 cSt $\left(3 \mathrm{~mm}^{2} \mathrm{~s}^{-1}\right)$ (Triest and Alemany, 2014). The density of this fluid can balance the ice pressure $\left(930 \mathrm{~kg} \mathrm{~m}^{-3}\right.$ at $0^{\circ} \mathrm{C}$ and $970 \mathrm{~kg} \mathrm{~m}^{-3}$ at $-40^{\circ} \mathrm{C}$ ); its freezing point is around $-120^{\circ} \mathrm{C}$; and its kinetic viscosity is reasonably low $\left(3 \mathrm{~mm}^{2} \mathrm{~s}^{-1}\right.$ at $25^{\circ} \mathrm{C}$ ) even though this value rapidly increases below $-30^{\circ} \mathrm{C}\left(12 \mathrm{~mm}^{2} \mathrm{~s}^{-1}\right.$ at $-55^{\circ} \mathrm{C}$, which is three times greater than with the usual mixture of kerosene D40 with hydrochlorofluorocarbon HCFC-141b). In addition, this fluid is environmentally friendly. Our tests in the laboratory have shown that it does not interfere with the OF-CEAS spectrum in case of contamination of the water (Triest and others, 2014). Furthermore, our tests in a cold room at $-10^{\circ} \mathrm{C}$, where we dropped ice chips into $3 \mathrm{~L}$ of silicone oil and let the mixture sit for $>6$ weeks, showed no cluster formation. Silicon oil rapidly forms a coating around each ice chip, preventing further ice sintering by direct contact.

Silicone oil 3 cSt nevertheless has two main drawbacks. It is relatively expensive $\left(\sim € 5 \mathrm{~kg}^{-1}\right.$, which is notably more expensive than ESTISOL ${ }^{\mathrm{TM}}$ fluids) and it has a very low surface tension $\left(\sim 20 \mathrm{mN} \mathrm{m}^{-1}\right.$, less than the surface tension of water). This was a problem when using a plastic impeller

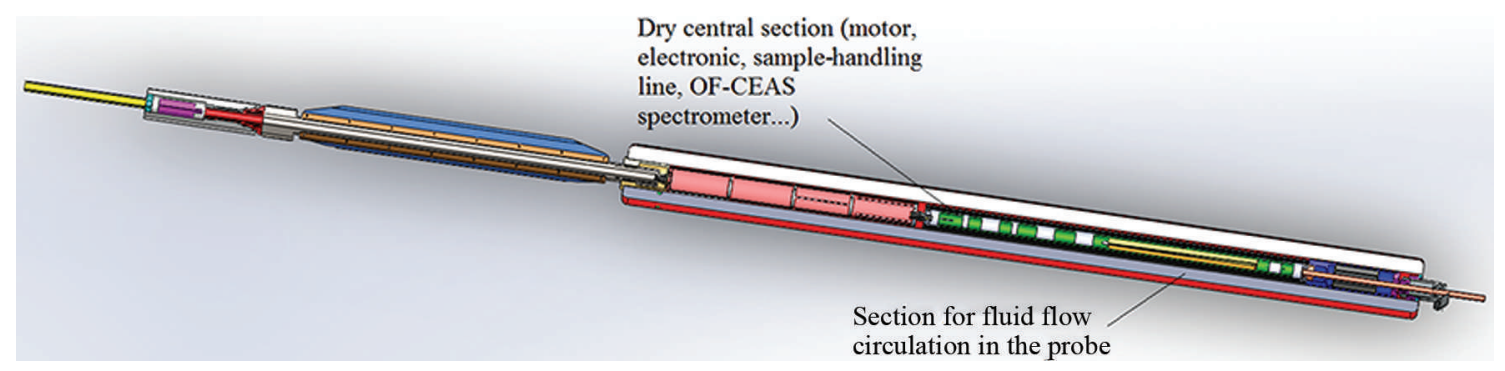

Fig. 2. Internal fluid circulation in the probe. 
Table 1. Fluid flow considerations for different concentrations of ice chips in the fluid

\begin{tabular}{|c|c|c|c|c|c|c|c|}
\hline \multirow[t]{2}{*}{$\begin{array}{l}\text { Drilling-fluid } \\
\text { flow rate }\end{array}$} & $\begin{array}{l}\text { Ice-chip flow rate } \\
\text { (at } 1.5 \mathrm{~mm} \mathrm{~s}^{-1} \\
\text { penetration rate) }\end{array}$ & $\begin{array}{c}\text { Ice-chip } \\
\text { concentration }\end{array}$ & $\begin{array}{l}\text { Fluid velocity in } \\
\text { annulus section }\end{array}$ & $\begin{array}{c}\text { Calculated } \\
\text { ice-chip velocity } \\
\text { in annulus section }\end{array}$ & $\begin{array}{l}\text { Regular head } \\
\text { loss on the } \\
\text { hydraulic line }\end{array}$ & $\begin{array}{c}\text { Pump } \\
\text { pressure }\end{array}$ & $\begin{array}{c}\text { Pump power } \\
\text { consumption } \\
\text { (with a } 40 \% \text { output) }\end{array}$ \\
\hline & $\mathrm{m}^{3} \mathrm{~s}^{-1}$ & $\%$ & $\mathrm{~ms}^{-1}$ & $\mathrm{~ms}^{-1}$ & $\mathrm{~m}$ & bar & W \\
\hline $\begin{array}{l}5 \times 10^{-4} \mathrm{~m}^{3} \mathrm{~s}^{-1} \\
\left(30 \mathrm{Lmin}^{-1}\right)\end{array}$ & $1.65 \times 10^{-5}$ & 2.3 & 0.051 & 0.05 & 110 & 9.5 & 1200 \\
\hline $\begin{array}{l}7 \times 10^{-4} \mathrm{~m}^{3} \mathrm{~s}^{-1} \\
\left(42 \mathrm{Lmin}^{-1}\right)\end{array}$ & $1.65 \times 10^{-5}$ & 1.64 & 0.07 & 0.068 & 245 & 22 & 4000 \\
\hline $\begin{array}{l}1 \times 10^{-3} \mathrm{~m}^{3} \mathrm{~s}^{-1} \\
\left(60 \mathrm{Lmin}^{-1}\right)\end{array}$ & $1.65 \times 10^{-5}$ & 1.15 & 0.1003 & 0.1 & 450 & 41 & 10000 \\
\hline
\end{tabular}

pump during our initial fluid loop tests in the laboratory. At some point, some fluid got passed between the impeller and housing, generating cavitation and the destruction of the impeller after a few hours of operation. Therefore the leaktightness of the pump will require special care.

\section{Hydraulic considerations}

The ice chips generated while cutting the ice will be transported to the surface by the circulation of drilling fluid. This fluid circulation will be generated by a high-pressure pump at the surface. To reduce the risk of clogging the borehole, we decided to reduce as much as possible the concentration of ice chips $(<5 \%$ of the volume). We also decided to seek the highest upward velocity possible. At the same time, the fluid flow rate must be kept low enough to minimize the regular (and additionally the singular) head loss (mainly in the hosepipe) on the hydraulic line, and consequently to minimize the power required by the pump. The rate of ice-chip production by the drill head is proportional to the probing speed. Considering the sample flow required by the OF-CEAS spectrometer $\left(\sim 1.5 \mathrm{~mL} \mathrm{~min}^{-1}\right.$ of gas) and the need to limit the power that will be provided to the thermal head, we set the probe penetration speed at $1.5 \pm 0.5 \mathrm{~mm} \mathrm{~s}^{-1}$.

Below we explain the method used to determine the best balance between the drilling fluid flow rate needed to minimize the ice-chip concentration at $1.5 \mathrm{~mm} \mathrm{~s}^{-1}$ penetration rate and the power required by the pump to generate this flow rate.

In our hydraulic calculations, we considered a two-phase flow with ice chips in motion in a fluid having its own flow rate. The ice-chip concentration is low enough $(<5 \%)$ to consider that there is no interaction between ice particles, and that chip motion is only due to the drag force exerted by the drilling fluid. In the flow range we are targeting (20$\left.60 \mathrm{~L} \mathrm{~min}^{-1}\right)$, the ice-chip velocity is similar to the drilling fluid velocity.

To determine the optimal hydraulic working point, the regular head loss was determined for different flow rates on a flowline going from the surface to the probe and then back to the surface (Alemany and others, 2014). The calculation takes into account the ice-chip production by the probe head, the drilling-fluid viscosity, the hosepipe and borehole geometry, and the temperature: first, for pure drilling fluid being injected between the hosepipe at the surface (point 1 in Fig. 1) and the probe (point 2 in Fig. 1); second, between the probe and another point at the surface (point 3 in Fig. 1) for chips mixed in drilling fluid. The drilling-fluid/ice-chips mixture is considered to be a homogeneous fluid based on the mean physical properties of each (Alemany and Mityar, 2007). In both cases, the head loss is calculated using the Bernoulli relationship (also known as the Darcy-Weisbach equation) between two points, which takes into account fluid viscosity and system geometry:

$$
H_{1}=\Delta H_{\text {pump-down }}=h_{2}+\Delta H_{1-2}
$$

and

$$
H_{2}+\Delta H_{\text {pump-up }}=H_{3}+\Delta H_{2-3}
$$

where $\Delta H$ is the head loss between two points (only regular head loss is considered, because singular head loss is negligible) and $H$ is the hydraulic load at one point. The regular head loss according to the Darcy-Weisbach equation is

$$
\Delta H_{\text {regular }}=\lambda \frac{L}{D_{\mathrm{h}}} \frac{U_{\text {fluid }}^{2}}{2 g}
$$

where $\lambda$ is the head loss coefficient calculated taking into account the Reynolds number, the fluid's viscosity and the relative roughness of the pipe.

$$
\frac{P_{1}}{\rho g}+\frac{U_{1}^{2}}{2 g}+Z_{1}=H_{1}
$$

where $P_{1}$ is the pressure at point $1, V_{1}$ is the fluid's velocity at point 1 , and $Z_{1}$ is the altitude at point 1 . The two calculated head losses are added to obtain the total head loss on the hydraulic circuit.

Calculations were done for different borehole sizes and hosepipe diameters. The results presented in Table 1 were obtained with the final set-up: borehole diameter of $120 \mathrm{~mm}$ and hosepipe OD of $44 \mathrm{~mm}$ (and hosepipe inner diameter (ID) $31.75 \mathrm{~mm}\left(1 \frac{1 / 4}{4} \mathrm{in}\right)$ ), hosepipe length of $3500 \mathrm{~m}$ and fluid physical properties considered at $-40^{\circ} \mathrm{C}$.

\section{SUBGLACIOR PROBE DESIGN \\ Probe}

The probe design includes elements to cut the ice, to melt $3 \%$ of the ice surface, to separate the gas sample from meltwater, to carry the gas sample to the OF-CEAS spectrometer, and to handle the water and gas flow after separation and analysis. It also includes the OF-CEAS spectrometer specifically designed to fit inside the probe.

\section{Drill head}

The cutting head and thermal head are located at the tip of the probe. In its current design (subject to change after additional tests on artificial ice in our cold rooms), the cutting head includes three large cutters $(49 \mathrm{~mm}$ instead of $15 \mathrm{~mm}$ 


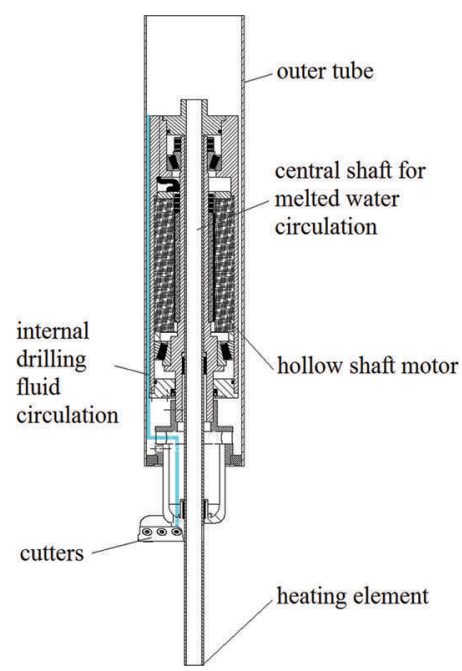

Fig. 3. Schematic of the lower part of the probe (drill head and motor section).

on most of the usual electromechanical drill heads) with adjustable shoes, and three holes allowing the drilling fluid to flow through the head and remove the ice chips from the cutters while drilling. The thermal head lies at the tip of the drill head. This heating element is fixed to the probe (not a rotating part) while the cutting head rotates around it (Fig. 3). The drill head is designed to minimize the risk of polluting the sample with drilling fluid. Laboratory tests have shown that the melted water produced by the heating element and the silicon fluid remain well separated by gravity without mixing because the water has a greater density than the drilling fluid. The thermal head has a $22 \mathrm{~mm}$ OD.

\section{Motor section}

The motor section driving the drill head lies just above the latter. The motor we selected is a brushless motor with a large hollow section in its centre (Kollmorgen Frameless motor ref: $\mathrm{KBMS}-17 \mathrm{H04}-\mathrm{C00}$, stall torque $=5.90 \mathrm{Nm}$, peak torque $=23.7 \mathrm{~N} \mathrm{~m}$, supply voltage $=400 \mathrm{~V}$ a.c., rated speed $=5775 \mathrm{rpm}$, with hall sensor option for servo commutation) allowing the water produced by the thermal head to get through and reach the gas/water separation section. This motor with its driver provides the right torque (close to $10 \mathrm{Nm}$ ) at the right rotation speed (60-120 rpm) without needing a gearbox. The OD of this motor (including a custom-made shield to protect it from the fluid) will range between 84 and $88 \mathrm{~mm}$.

\section{Sample-handling section}

The sample-handling line is located above the motor section. While drilling, the probe should be able to deliver a $1.5 \mathrm{~mL} \mathrm{~min}^{-1}$ gas flow to the OF-CEAS spectrometer from the meltwater produced in the lower part of the probe by the thermal head. In the ice, the trapped gas concentration is close to $10 \%$ of the volume, so the water flow produced by the thermal head needs to be $\sim 15 \mathrm{~mL} \mathrm{~min}^{-1}$. The latter will be attained by using heating elements embedded in a ceramic body. The tip will concentrate most of the heating power, while the outer surface of the thermal tube will be heated to a temperature just above the pressure-melting point.

The sample flow produced at ambient pressure (between 10 bar at $100 \mathrm{~m}$ and 300 bar at $3000 \mathrm{~m}$ ) will be pumped into the probe through a gas/liquid separation device. So far, the

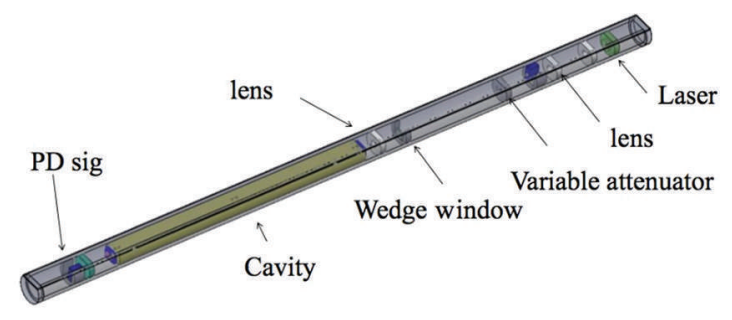

Fig. 4. Schematic of the OF-CEAS laser spectrometer adapted to the SUBGLACIOR probe.

choice for the separation device has not yet been made. Two options are still being considered: a debubbler or a membrane. The sample gas pressure inside the OF-CEAS spectrometer cavity will be 20 mbar. Therefore, the samplehandling device must work under a significant pressure gradient. Membranes are known to be able to operate under such high pressure gradients. Because the gas flow rate through a membrane is proportional to the membrane's surface area, we can play with its geometry to obtain the required pressure drop and gas flow downstream. The meltwater then remains at ambient pressure and can be delivered back into the borehole through a nozzle that produces droplets which will refreeze immediately into ice chips. This option will make the sample-handling line simpler than the second option described below, and different types of membrane are currently under investigation.

If the membrane option proves to be unsuitable, the second solution is to use a debubbler to separate gas from liquid water. The water/gas sample mixture must first be expanded from ambient pressure to atmospheric or subatmospheric pressure, using a dedicated pressure regulator able to handle a two-phase sample. We already found a miniature pressure regulator able to expand a liquid/gas mixture from $>400$ bar to $<10$ bar (Tescom BB- 1 series, Les Automatismes Appliquées, Meyreuil, France). Another expansion step from 10 bar to sub-atmospheric pressure can then easily be obtained with several brands of miniature pressure regulators. The debubbler has been used for many years in continuous-flow analysis systems in the laboratory and has recently been adapted for gas measurements (Chappellaz and others, 2013). The 20 mbar cavity pressure following the debubbler will be obtained with a built-in membrane pump installed downstream of the cavity, with possibly an intermediate membrane working at sub-ambient pressure. This solution requires pressurizing the meltwater back to ambient pressure, in order to inject it into the borehole with a nozzle to produce droplets. For both solutions, once pumped through the OF-CEAS cavity, the gas sample will be stored in a tank inside the probe. The whole gas volume to be sampled during a probe run through $3000 \mathrm{~m}$ of ice will represent a few tens of litres at standard temperature and pressure and can thus easily be stored inside the probe.

\section{OF-CEAS laser spectrometer adapted for SUBGLACIOR}

The key to the project was to design and build a laser spectrometer that fitted in a $50 \mathrm{~mm}$ OD tube. In the probe, the spectrometer is located above the sample-handling section. The built-in spectrometer currently being developed is based on the principle of OF-CEAS (Morville and others, 2014). It uses a distributed feedback diode laser at $2.4 \mu \mathrm{m}$ that is injected in a high-finesse ( $\mathrm{V}$-shape) optical cavity 


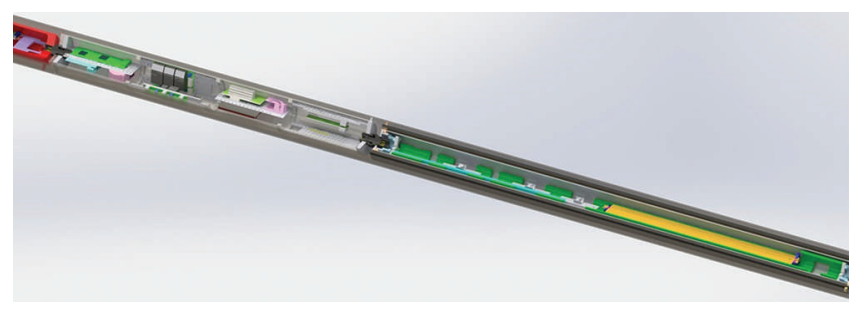

Fig. 5. Schematic of the OF-CEAS spectrometer with its thermal regulation shield.

(Fig. 4). Methane and the water deuterium isotope ratio will be analysed simultaneously, with a sensitivity of $1 \mathrm{ppb}$ for methane and $\sim 1 \%$ o for $\delta \mathrm{D}$ of $\mathrm{H}_{2} \mathrm{O}$ within 1 min integration time (representing 6-12 cm of ice sample during probing).

The spectrometer is contained in two aluminium tubes of $50 \mathrm{~mm}$ OD and $40 \mathrm{~mm}$ ID assembled together which contain the laser diode, the stainless-steel cavity and the optical parts. The laser diode is installed on the cylinder axis of the aluminium tubes, at a distance from the cavity equivalent to the cavity length, i.e. $\sim 500 \mathrm{~mm}$. The laser and the optical cavity are aligned by displacing two planoconvex lenses with focals chosen to mode-match the laser beam to the fundamental mode of the resonator (Fig. 5). A wedge window mounted on an electromechanical translator, placed between the laser and the cavity, controls the optical path length between the laser and the cavity (in order to adjust the phase of the electromagnetic field feeding back to the laser (Morville and others, 2005). A photodiode is placed at the cavity output to record the transmitted signal while the internal detector embedded in the laser diode is used as the reference photodiode. The overall length of the spectrometer is $\sim 1200 \mathrm{~mm}$. The diameter of the OF-CEAS system was calculated to provide a good compromise between compactness and robustness of the optical system. The spectrometer has been built and is currently undergoing laboratory tests.

In order to provide optimal measurements, notably of the deuterium/hydrogen isotopic ratio of water, the OF-CEAS laser spectrometer must be maintained at a constant temperature $\left((20-40) \pm 0.05^{\circ} \mathrm{C}\right)$ and should be protected from shocks and vibrations. Temperature stabilization is achieved using insulation stages and thin heating elements. The temperature regulation system must fit in the electronics section within an $84 \mathrm{~mm}$ ID.

The dry outer tube housing the instrument is kept under low pressure ( $\sim 20$ mbar) which acts as acoustic isolation and thermal insulation together with a $5 \mathrm{~mm}$ thick layer of Spaceloft soft insulation. Heat is supplied by a $2 \mathrm{~mm}$ thick heating mat controlled by a PID controller (proportionalintegral-derivative controller, which is a control loop feedback mechanism). This regulation set-up was tested in a cold room at the LGGE and we found that the power consumption needed to keep the spectrometer at a temperature of $+20^{\circ} \mathrm{C}$ in a $-40^{\circ} \mathrm{C}$ room is $\sim 30 \mathrm{~W}$. This result is very promising. Vibration control is currently under investigation but we have not yet reached the final design. This will involve dedicated elastomeric dampers at both ends (top and bottom) of the OF-CEAS spectrometer inside the dry outer tube, with hermetic connections for the gas lines and power and electrical connections.

\section{Data and power transfer between the surface and the probe}

In the SUBGLACIOR probe, two components must be controlled while drilling: the probe itself and the OF-CEAS instrument. The spectrometer requires a considerable amount of data transfer from the probe to the surface in order to check in real time the instrument status as well as the deuterium/hydrogen isotopic ratio and methane concentration data. The probe requires fast response times of both the electromechanical drill motor and the thermal head control. In our design, the spectrometer data transfer relies on an embedded PC and an ADSL transmission card, which also controls the spectrometer following data analysis at the surface. ADSL can handle large volumes of data transfers. However, its reliability under start-stop cycles and temperature changes must be further tested.

Data transmission is handled in the main cable through two branches. One branch (Fig. 6) is dedicated to the spectrometer data transmission through the ADSL card and a twisted pair of conductors in the cable. The second branch is dedicated to the probe drilling control through an FSK (frequency shift keying) transmission card and a second twisted pair of conductors. Electronic components (including the PC) are located above the OF-CEAS spectrometer.

The cable also transfers electric power from the surface to the probe. The probe design is intended to minimize the power required, in order to limit the logistics (power generator and associated fuel). The power budget of the SUBGLACIOR probe is determined following operation of all internal components separately in a cold room: (1) a first drill-head prototype at $-20^{\circ} \mathrm{C}$ to drill a block of artificial ice, (2) the thermal regulation system to maintain a stainlesssteel cylinder model with the same dimension as the spectrometer at $+20^{\circ} \mathrm{C}$ in a $-40^{\circ} \mathrm{C}$ cold room, and (3) the thermal head on a block of artificial ice at $-20^{\circ} \mathrm{C}$. These tests lead to an overall power requirement of $<1 \mathrm{~kW}$ (Table 2).

All electrical probe components will run on direct current (d.c.). With d.c., the higher the voltage, the lower the loss on the transmission line for a given power consumption. However, very high voltage at the surface is difficult to generate and can be harmful for the operating staff. Our choice results from a compromise between very highvoltage d.c. and the technical limits of the electrical components available. We will use an $800 \mathrm{~V} / 5 \mathrm{~A}$ d.c. power supply at the surface, which will provide $280 \mathrm{~V}$ and a $5 \mathrm{~A}$

Table 2. Power requirement of the SUBGLACIOR probe

\begin{tabular}{|c|c|c|c|c|c|}
\hline & $\begin{array}{c}\text { Probe motor } \\
\text { (electromechanical drill) }\end{array}$ & Thermal head & $\begin{array}{l}\text { Sample-handling line } \\
\text { (including injection of } \\
\text { fluid in borehole) }\end{array}$ & $\begin{array}{c}\text { OF-CEAS } \\
\text { laser spectrometer } \\
\text { consumption }\end{array}$ & $\begin{array}{l}\text { OF-CEAS } \\
\text { laser spectrometer } \\
\text { thermal regulation }\end{array}$ \\
\hline Power required $(\mathrm{W})$ & 150 & 300 & 100 & 100 & 100 \\
\hline
\end{tabular}




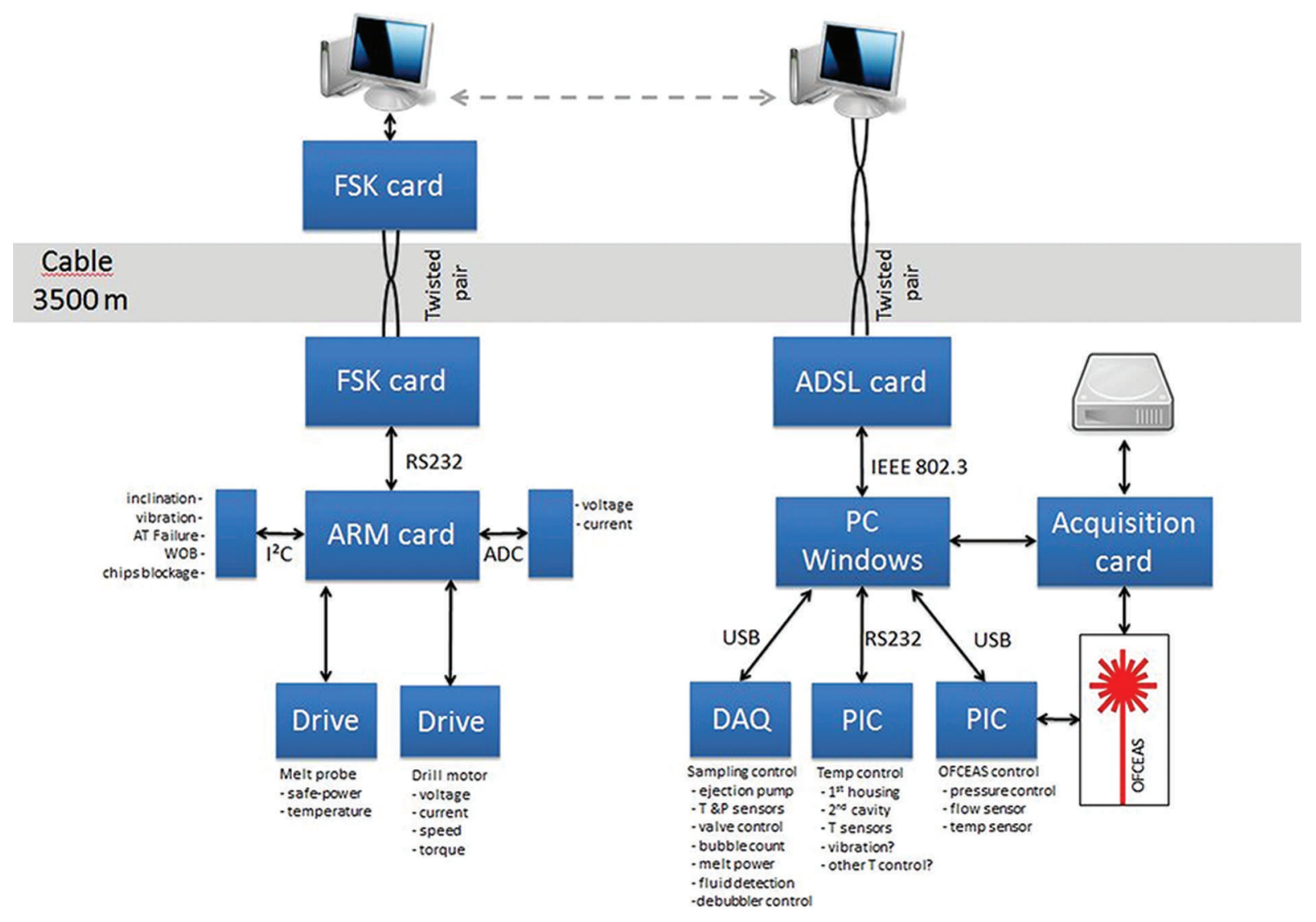

Fig. 6. Schematic of the date transmission lines.

current at the probe end (taking into account losses along the line). Apart from the motor and the thermal head, all other electrical components require a lower voltage. The $280 \mathrm{~V}$ power supply will thus be transformed into two additional $24 \mathrm{~V}$ power lines: one dedicated to the spectrometer and the other for the heating mats used to maintain the spectrometer at the right temperature.

\section{Anti-torque section}

The design of the anti-torque sections is similar to the usual ice-core drilling systems (Fig. 7). It is placed at the very top of the probe. It will compensate for the torque generated by the electromechanical drill head. At the top of the antitorque section there are two slip rings, one for the cable (power and data transfer) and a hydraulic one for the hosepipe (drilling fluid). A central hollow channel will allow the drilling fluid to travel through the anti-torque section.

\section{Cable}

The cable will enable handling of the probe from the surface, by supporting its own weight, the hosepipe weight and the probe. It contains electrical conductors allowing

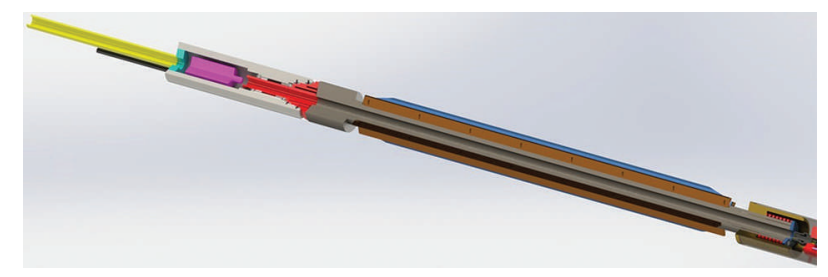

Fig. 7. Schematic of the anti-torque section. power and data transmission (Fig. 6). The cable design will be similar to that commonly used for ice-core drills (Fig. 8). The inner parts will consist of two insulated electrical conductors (A) and two insulated twisted pair conductors (B). The outer part of the cable will include two layers of steel wire $(C)$ for strength.

\section{Hosepipe}

The hosepipe will transfer the cleaned drilling fluid from the surface down to the probe. The ID of the hosepipe is $1 \frac{1 / 4}{4}$ in (31.75 mm).

The hosepipe will not contribute to mechanical handling of the probe; this will fully rely on the cable. Its own weight will also be reduced even when entirely unspooled as it will be immersed in the drilling fluid and be attached to the cable at regular intervals (every $20 \mathrm{~m}$ ). This technique has been successfully used up to $200 \mathrm{~m}$ during hot-water drilling

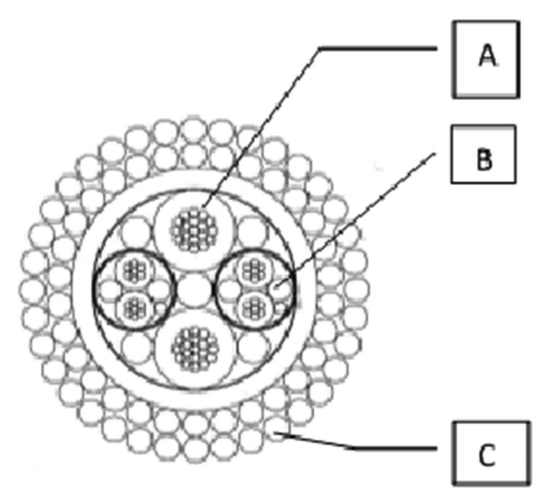

Fig. 8. Schematic of the cable. 


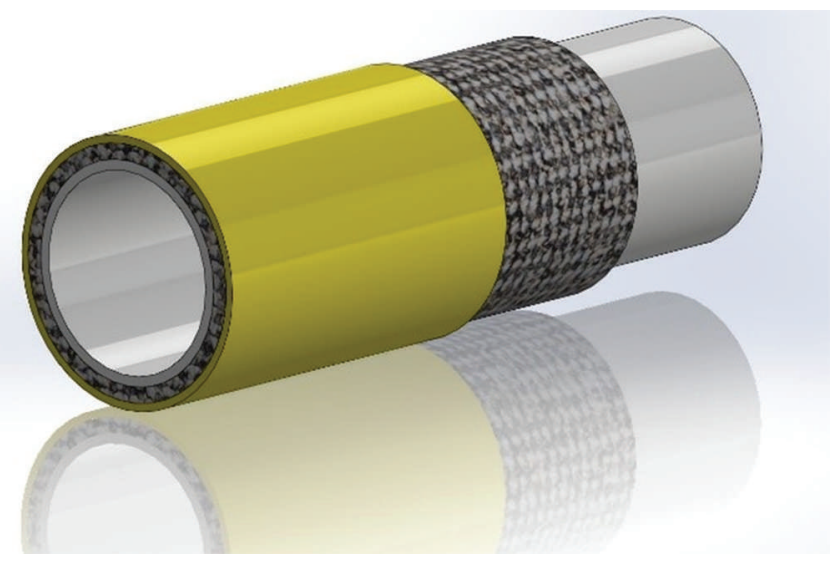

Fig. 9. Schematic of the hosepipe.

operation in the European Alps by LGGE and up to $2000 \mathrm{~m}$ during the IceCube project at South Pole (Koci, 2002). The hosepipe may be raised and lowered in the borehole several times per season in case repair of the probe is required, so it must withstand abrasion against the ice. In order to reduce the pressure loss along the length of the hosepipe, both the inside and outside surfaces should be smooth and cause minimum friction loss.

Ambient temperature in the borehole can be as low as $-55^{\circ} \mathrm{C}$. This is rather severe for a hosepipe. At the surface where the hosepipe will be bent the operating temperature will be slightly higher, -25 to $-40^{\circ} \mathrm{C}$. The hosepipe must thus withstand spooling/unspooling onto its drum at these low temperatures without suffering permanent damage. The spooler drum and gooseneck will provide the largest possible bending radii. We may also consider slightly heating the drill fluid just before its entry into the hosepipe on the spooler side, in order to warm up the hosepipe in its most thermally stressed sections.

The hosepipe will include several layers (Fig. 9). The inner and outer material will be compatible with long-term immersion in silicone oil at low temperatures. The intermediate layer (providing the hosepipe strength) will use Aramid fiber, or similar products, to optimize flexibility.

\section{Winch and spooler}

The complete winching system will consist of a winch (for the cable) and a spooler (for the hosepipe) (Fig. 10).

The probe will first be installed horizontally. A tilting mast will then raise it vertically so that the cable and hosepipe can be connected once the probe has been lowered a little into the borehole. During the probe's descent, the cable and hosepipe will be attached together at regular intervals, so that the cable will carry some of the hosepipe weight and also so that the two strings will stay together.

The cable winch will control the ascent and descent speed of the probe and will handle the load of the whole system $(\sim 0.5 \mathrm{t})$. The hosepipe spooler will follow the cable winch as a 'slave'. For that purpose, the hosepipe will be spooled at the appropriate speed by keeping it at a constant tension, measured at the gooseneck.

The master-slave control between the winch speed and the spooler will be controlled through a PLC (programmable logic controller). The operator set the winch cable speed and the PLC will control the spooler speed and the hose tension. To do this, the PLC will rely on inputs from

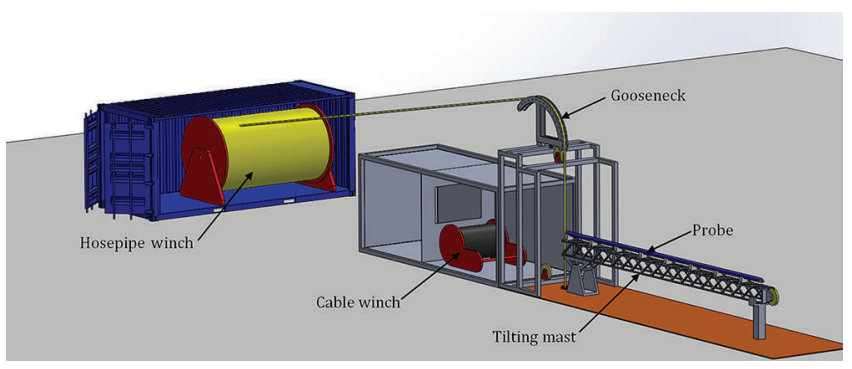

Fig. 10. Schematic of surface equipment.

the load cells and/or encoders on the gooseneck and cable sheave wheel.

\section{Surface pump and chip recovery}

The surface pump has not yet been chosen at this stage of the project design. It will have to provide the right fluid flow rate under sufficient pressure to compensate for the head loss on the hydraulic line. It should furthermore be able to work at an ambient temperature as low as $-40^{\circ} \mathrm{C}$. Regarding ice-chip recovery, we intend to continuously pump the fluid/chip mixture as it reaches the top of the casing at the same flow rate as the flow injected into the hosepipe. The mixture will then go into a set of filtering containers that can be bypassed one after the other to allow the container to be cleaned once the filter is saturated with ice chips.

\section{CONCLUSIONS}

After 2 years of research and development on the SUBGLACIOR probe, the project is now reaching maturity. Nearly all the technological challenges raised by the probe design have been resolved. The only major difficulty remaining concerns the sample handling. The solution to this will rely on the characteristics of the tested membranes for sample extraction at ambient pressure or, if the final sample-handling solution requires working at atmospheric or sub-atmospheric pressure, on our ability to re-inject the expanded sample into the borehole. The OF-CEAS laser spectrometer that will be embedded in the probe has now been built and tested in the laboratory. So far, it operates according to expectations.

We have successfully tested the instrument's behavior, as well as gas extraction through a membrane (but under different boundary conditions than for the glaciological application), under open-ocean conditions during summer 2014. The coming austral summer will be used at Concordia Station to test the circulation of drilling fluid in the borehole now equipped with our new leak-tight casing. It will also allow us to evaluate the performance of different designs of electromechanical drill heads. The true test of the whole SUBGLACIOR probe is planned to take place at Concordia Station during the 2016/17 austral summer. The signals to be measured by the probe are already known from the EPICA Dome $\mathrm{C}$ deep drilling, thus providing the best conditions for qualifying the instrument. If this test is a success, the SUBGLACIOR probe will be available for the ice-core community to qualify potential 'oldest ice' sites of the East Antarctic plateau during the following field seasons.

During a typical drilling season, the plan is for the SUBGLACIOR probe to run continuously 24 hours a day and to stop only to bring the probe back to the surface. We 
plan to run the system with three shifts, each managed by three operators. The whole system will require the logistical support of a terrestrial traverse to transport the equipment but also to host the team and provide energy to the drilling system. The current estimation of the total volume needed for the drilling equipment (not taking into account the logistic needs such as power generator, fuel, etc.) is close to eight containers, of which four would be dedicated to transporting the drilling fluid.

\section{ACKNOWLEDGEMENTS}

The research leading to these results has received funding from the European Community's Seventh Framework Programme ERC2011 under grant agreement No. 291062 (ERC Ice\&Lasers) and from the French Agence Nationale de la Recherche (ANR) under grant agreement No. SIM156ANR-11-BS56-0019 (ANR SUBGLACIOR). This project has been conducted thanks to the technical support of the French Drilling and Coring Facility (C2FN - Ice). Additional funding support was provided by the BNP Paribas Foundation as well as 'Equipement d'Excellence' EquipEX CLIMCOR (ANR-11-EQPX-0009-CLIMCOR). Fieldwork is supported by IPEV (the French polar institute, through the 'SUBGLACIOR' project No. 1119) and PNRA (the Italian Antarctic programme) at Concordia Station. We thank the two anonymous reviewers and the editor, Pavel Talalay, for helpful comments.

\section{REFERENCES}

Alemany $\mathrm{O}$ and Mityar $\mathrm{H}$ (2007) Viscosity and density of a twophase drilling fluid. Ann. Glaciol., 47, 141-146 (doi: 10.3189/ 172756407786857712)

Chappellaz J, Brook E, Blunier T and Malaizé B (1997) $\mathrm{CH}_{4}$ and $\delta^{18} \mathrm{O}$ of $\mathrm{O}_{2}$ records from Antarctic and Greenland ice: a clue for stratigraphic disturbance in the bottom part of the Greenland Ice Core Project and the Greenland Ice Sheet Project 2 ice cores. J. Geophys. Res., 102(C12), 26547-26557 (doi: 10.1029/ 97JC00164)

Chappellaz J and 12 others (2013) High-resolution glacial and deglacial record of atmospheric methane by continuous-flow and laser spectrometer analysis along the NEEM ice core. Climate Past, 9(6), 2579-2593 (doi: 10.5194/cp-9-2579-2013)

Clow GD and Koci B (2002) A fast mechanical-access drill for polar glaciology, paleoclimatology, geology, tectonics and biology. Mem. Natl Inst. Polar Res., Special Issue 56, 5-37
Duphil R, Possenti P and Piard L (2014) A new leak-tight borehole at Dome Concordia Station, Antarctica, for the SUBGLACIOR project. Ann. Glaciol., 55(68) (doi: 10.3189/2014AoG68A022) (see paper in this issue)

Fischer $\mathrm{H}$ and 23 others (2013) Where to find 1.5 million yr old ice for the IPICS 'Oldest-Ice' ice core. Climate Past, 9(6), 2489-2505 (doi: 10.5194/cp-9-2489-2013)

Gillet F, Rado C, Marec G, Maitre M, Perrin J and Ricou G (1984) 'Climatopic' thermal probe. CRREL Spec. Rep. 84-34, 95-99

Koci B (1994) The AMANDA project: drilling precise, largediameter holes using hot water. Mem. Natl Inst. Polar Res., Special Issue 49, 203-211

Koci B (2002) Wotan: a drill for Ice Cube. Mem. Natl Inst. Polar Res., Special Issue 56, 209-216

Lisiecki LE and Raymo ME (2005) A Pliocene-Pleistocene stack of 57 globally distributed benthic $\delta^{18} \mathrm{O}$ records. Paleoceanography, 20(PA1), PA1003 (doi: 10.1029/2004PA001071)

Makinson K (1994) BAS hot water drilling on Ronne Ice Shelf, Antarctica. Mem. Natl Inst. Polar Res., Special Issue 49, 192-202

Morville J, Kassi S, Chenevier M and Romanini D (2005) Fast, lownoise, mode-by-mode, cavity-enhanced absorption spectroscopy by diode-laser self-locking. Appl. Phys. B, 80(8), 1027-1038 (doi: 10.1007/s00340-005-1828-z)

Morville J, Romanini D and Kerstel E (2014) Cavity enhanced absorption spectroscopy with optical feedback. In Gagliardi G and Loock H-P eds Cavity-enhanced spectroscopy and sensing. Springer, Berlin, 163-209

Nguyen JP (1993) Techniques d'exploitation pétrolière: le forage. Éditions Technip, Paris

Philberth K (1962) Une méthode pour mesurer les températures à I'intérieur d'un inlandsis. C.R. Séances Acad. Sci. (Paris), 254(22), 3881-3883

Schwander J, Marending S, Stocker T and Fischer H (2014) RADIX: a minimal-resources rapid-access drilling system. Ann. Glaciol., 55(68), 34-38 (doi: 10.3189/2014AoG68A015) (see paper in this issue)

Suto $Y$ and 6 others (2008) Laboratory experiments and thermal calculations for the development of a next-generation glacierice exploration system: development of an electro-thermal drilling device. Polar Sci., 2(1), 15-26 (doi: 10.1016/j.polar. 2008.02.002)

Talalay PG, Zagorodnov VS, Markov AN, Sysoev MA and Hong J (2014) Recoverable autonomous sonde (RECAS) for environmental exploration of Antarctic subglacial lakes: general concept. Ann. Glaciol., 55(65), 23-30 (doi: 10.3189/ 2014AoG65A003)

Triest J and Alemany $O$ (2014) Drill fluid selection for the SUBGLACIOR probe: a review of silicone oil as a drill fluid. Ann. Glaciol., 55(68) (doi: 10.3189/2014AoG68A028) (see paper in this issue) 